\title{
Pembelajaran Integratif: Menyimak Puisi dan Menulis Cerita Pendek
}

\author{
Dewi Syafrina ${ }^{1, *}$ \\ Universitas Negeri Malang \\ *Corresponding author. Email: syafrina.dewinova@gmail.com
}

Submitted: 3 Augst $2021 \quad$ Revised: 31 Oct $2021 \quad$ Accepted: 1 November 2021

\begin{abstract}
Language skills are commonly integrated in Indonesian language learning. In this integration, student activities involving listening and reading skills will lead to speaking and writing activities. However, in the learning process, the integration is always related to the same type of text. In fact, teachers can combine different types in learning Indonesian. Therefore, the aim of this article is to explain the integration of listening poetry and writing short stories. The integration will be explained in the discussion section in which the relationship between listening poetry and writing short stories and the implementation in Indonesian language learning are discussed. This article is expected to be used as a reference in Indonesian language learning so that there is an involvement of various texts in writing short stories.
\end{abstract}

Key words. language skills; integration learning; listening to poetry; writing short stories

Abstrak. Pengintegrasian keterampilan berbahasa dalam pembelajaran bahasa Indonesia sudah umum dilakukan. Dalam pengintegrasian tersebut aktivitas siswa yang melibatkan keterampilan menyimak dan membaca akan berujung pada aktivitas berbicara dan menulis. Namun, dalam proses pembelajaran, pengintegrasian tersebut selalu terkait pada jenis teks yang sama. Pada kenyataannya, guru dapat mengombinasikan jenis yang berbeda dalam pembelajaran bahasa Indonesia. Oleh karena itu, artikel ini memaparkan pengintegrasian menyimak puisi dan menulis cerita pendek. Hal tersebut akan dipaparkan dalam pembahasan mengenai keterkaitan menyimak puisi dengan menulis cerpen dan implementasinya dalam pembelajaran bahasa Indonesia. Pembahasan dalam artikel ini diharapkan dapat dijadikan masukan dan rujukan untuk diimplementasikan dalam pembelajaran bahasa Indonesia sehingga terdapat keterlibatan teks yang beragam dalam menulis cerita pendek.

Kata kunci. keterampilan berbahasa; pembelajaran integrasi; menyimak puisi; menulis cerita pendek.

\section{Pendahuluan}

Pembelajaran bahasa Indonesia pada dasarnya dilaksanakan secara terpadu dalam melibatkan empat keterampilan berbahasa. Pada hakikatnya proses pembelajaran selalu diawali dengan kegiatan reseptif (menyimak atau membaca) dan diakhiri dengan kegiatan produktif (berbicara atau menulis). Kepaduan antarketerampilan berbahasa dalam pembelajaran bahasa Indonesia inilah yang menunjukkan pelaksanaan pembelajaran integratif.

Dalam proses perencanaan dan pembelajaran kegiatan reseptif, guru lebih sering menyajikan teks tertulis dibandingkan teks lisan sehingga siswa lebih sering diminta membaca 
dibandingkan menyimak (Syafrina, 2017). Hal ini terjadi karena pembelajaran keterampilan menyimak tidak terdapat dalam perencanaan pembelajaran yang disusun oleh guru (Syafrina, dkk., 2017). Selain itu, dalam kurikulum, guru diberikan kebebasan untuk memilih teks secara lisan atau tertulis sebagai materi dan menugaskan siswa memproduksi teks secara tertulis atau lisan. Kebebasan tersebut menjadikan salah satu keterampilan reseptif siswa terlalu dominan dalam pembelajaran.

Selain kedominanan keterampilan membaca dibandingkan keterampilan menyimak dalam pembelajaran bahasa Indonesia, keterkaitan antara keterampilan berbahasa reseptif dan produktif berada dalam satu genre teks saja. Sebagai contoh, guru mempersiapkan cerita pendek untuk dibaca atau diperdengarkan kepada siswa agar pada akhirnya siswa dapat menulis cerita pendek pula; siswa membaca teks eksposisi dengan tujuan mereka dapat menulis teks eksposisi pula. Kegiatan pembelajaran ini seperti ingin menunjukkan bahwa untuk menghasilkan sebuah jenis teks, siswa hanya perlu atau harus membaca teks dengan genre yang sama. Jika untuk memperkenalkan struktur teks, hal ini masih wajar. Namun, sumber inspirasi siswa dalam menulis teks tidak hanya mereka dapatkan dengan membaca atau menyimak teks dengan genre yang sama. Produksi bahasa siswa dapat tumbuh dari teks yang dibaca atau yang didengarnya (Harmer, 2007). Dengan arti kata, teks lisan maupun tertulis dalam genre apa saja dapat digunakan sebagai stimulus bagi siswa dalam menghasilkan teks lainnya.

Pada artikel ini penulis akan memaparkan pengintegrasikan keterampilan menyimak dan menulis dengan genre teks yang berbeda. Teks lisan yang digunakan sebagai stimulus adalah puisi agar kemmudian siswa dapat menulis cerita pendek. Hal ini berkaitan dengan permasalahan siswa dalam menulis cerita pendek yang terdapat dalam aspek penyajian isi cerita pendek yang masih miskin gagasan, kesulitan meramu ide, dan pemilihan kosakata yang kurang bervariasi (Putra, 2013). Permasalahan yang dihadapi oleh siswa menunjukkan bahwa daya imajinasi siswa masih kurang berkembang (Umar, 2016). Kesulitan lainnya yang dihadapi siswa adalah menentukan topik, membuat dan mengembangkan kerangka, merangkai peristiwa menjadi alur, menentukan konflik, dan menyusun kalimat efektif serta paragraf yang baik (Dewi, dkk., 2016)

Aspek yang menjadi permasalahan dalam menulis cerpen yang berkaitan dengan pencarian ide dan pengembangan diksi yang tepat dapat distimulus melalui membaca ataupun menyimak puisi. Sebagai stimulus untuk menulis cerita pendek, puisi memiliki ciri khas pada diksi. Puisi mengandung diksi yang padat; satu kata atau satu larik mengandung banyak makna yang dapat diinterpretasikan berdasarkan sudut pandang pembaca. Menyimak puisi dipilih dibandingkan dengan membaca puisi karena dengan menyimak siswa dapat menikmati suasana yang terkandung di dalam puisi melalui pembacaan orang lain dibandingkan dengan membacanya sendiri. Siswa juga dapat merasakan penghayatan yang sama terhadap puisi yang diperdengarkan. Melalui pemaknaan puisi yang disimak, siswa dapat mengambil tema, suasana, serta diksi untuk membantu mereka dalam menulis cerpen. Pada poin selainjutnya penulis akan menjelaskan pengintegrasian menyimak puisi dan menulis cerita dan pengimplementasiannya di lapangan. 


\section{Pembahasan}

\section{Keterkaitan Menyimak Puisi dan Menulis Cerpen}

Puisi merupakan bentuk karya sastra yang memiliki tiga sifat, yaitu (a) intuitif, (2) imajinatif, dan (3) sintetik. Sifat intuitif menghasilkan ciri ekspresif dan segustif; sifat imajinatif menghasilkan ciri konotatif; sifat sintetik menghasilkan ciri kesatuan, pemadatan, dan serba makna (Semi, 2008). Puisi membantu perkembangan bahasa dan meningkatkan keterampilan literasi siswa; menawarkan ruang berpikir untuk merefleksikan kehidupan sehingga meningkatkan pemahaman tentang diri pembaca atau pendengarnya melalui keterlibatan pribadi dengan sebuah puisi (Simecek \& Rumbold, 2016). Puisi juga dapat membangkitkan indera, menghubungkan diri sendiri dengan orang lain, dan menuntun pembaca atau pendengar untuk berpikir dengan cara mensintesis, seperti yang disyaratkan pada penggunaan bahasa metafora (Hughes, 2007). Oleh karena itu, puisi dapat dilihat sebagai karya sastra yang memiliki keunikan dan keunggulan dibandingkan dengan teks sastra lainnya.

Keunggulan yang dimiliki oleh puisi dapat membantu siswa mengembangkan kemampuannya dalam berpikir kreatif dan menulis cerita pendek. Dalam menulis cerita pendek siswa memerlukan kepekaan terhadap lingkungan sekitarnya agar dapat memperoleh ide cerita. Siswa juga membutuhkan banyak kosakata untuk menerjemahkan fenomena yang mereka amati menjadi sebuah ide dan mengembangkannya menjadi tulisan utuh. Kepekaan terhadap lingkungan dan hubungannya dengan diri sendiri, kekayaan bahasa, serta kemampuan siswa mencari makna itulah yang mereka dapatkan dari menyimak puisi. Berdasar pada sisi psikofisiologi, neuroimaging, dan respons perilaku, puisi yang dibacakan dapat bertindak sebagai stimulus yang kuat untuk memunculkan respons emosional puncak pada seseorang (Wassiliwizky, et al., 2017).

Ketika siswa menyimak puisi yang dibacakan, siswa akan mendapatkan pemahaman yang lebih baik tentang makna puisi tersebut (Hughes, 2007). Selain itu, perhatian terhadap bahasa dan ritme puisi berfungsi untuk memperluas kosa kata lisan dan tulisan. Anak-anak dengan keterampilan lisan yang berkembang dengan baik lebih mungkin untuk memiliki prestasi yang lebih tinggi dalam membaca dan menulis juga (Cazden, 1988; Chall, 2000; Collins, 2001). Setelah menyimak puisi secara bersama-sama, guru dapat melibatkan siswa dalam diskusi. Kegiatan berdiskusi tersebut dapat mengembangkan literasi siswa: membuat kesimpulan, mengidentifikasi ide utama, membuat penilaian dan menarik kesimpulan, mengklarifikasi dan mengembangkan sudut pandang, dan membuat koneksi (Hughes, 2007). Kemampuan inilah yang juga dibutuhkan saat siswa menulis cerita pendek. Oleh karena itu, penyair menekankan pentingnya mendengarkan puisi yang dibacakan dan menggali makna yang lebih dalam melalui diskusi dengan orang lain (Hughes, 2007).

Dengan mengetahui adanya keterkaitan antara fungsi menyimak puisi terhadap kemampuan menulis cerpen bagi siswa (karena mendukung perkembangan bahasa, kepekaan terhadap lingkungan, mengenal diri sendiri, mengeksplorasi pengalaman, dll) guru dapat pembelajaran bahasa Indonesia memaksimalkan pembelajaran menyimak puisi. Pembahasan di atas disimpulkan dalam diagram berikut. 


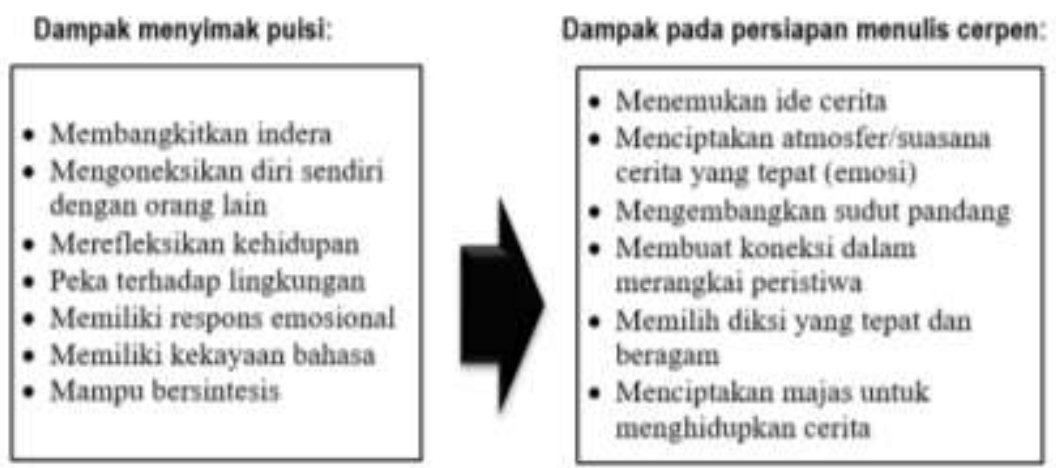

Gambar 1. Dampak Menyimak Puisi pada Persiapan Menulis Cerita Pendek

Setelah menyimak puisi, kemudian siswa dan guru terlibat dalam diskusi untuk memahami puisi tersebut, siswa memperoleh pengetahuan awal yang dapat menjadi bekal mereka dalam menulis cerita pendek. Seperti pada Gambar 1. menyimak puisi memberikan dampak pada kemampuan siswa dalam berbahasa, kepekaan terhadap lingkungan sekitarnya, serta dapat merefleksikan kehidupan. Hal ini mempermudah siswa dalam mengembangkan imajinasi, menemukan ide, mengenal diri sendiri dan orang lain untuk dijadikan bekal cerita pendek. Dengan cara itulah pengetahuan awal siswa aktif. Pengaktifan pengetahuan awal siswa merupakan salah satu metode yang dapat membantu siswa sebelum mereka mulai menulis; memastikan siswa berpikir tentang hal-hal yang sudah mereka ketahui sebelum menulis; memasukkan informasi baru ke dalam struktur pengetahuan yang ada yang mengaktifkan memori jangka panjang (Watt-Taffe \& Truscott, 2000).

Membangun pengetahuan awal sebagai bekal penemuan ide bagi siswa berkaitan dengan kesulitan siswa dalam mendesain plot cerita. Sebanyak $77 \%$ siswa bermasalah dalam hal tersebut karena kesulitan mereka dalam menemukan tema unik yang menarik bagi pembaca sasaran (Pratiwi, 2019). Kesulitan menemukan tema membuat siswa tidak dapat menyusun draf cerita. Hal ini menghambat proses penulisan karena karakter, latar, deskripsi, dan urutan peristiwa yang diperlukan harus disajikan secara kohesif untuk menunjukkan ide struktur cerita dan menarik minat pembaca (Dunn \& Finley, 2010)

Saat siswa dan guru mendiskusikan makna puisi yang sudah disimak secara bersama-sama, mereka juga akan menemukan bahasa figuratif atau majas di dalamnya dan mencari tahu makna di bentuk kiasan tersebut. Bahasa figuratif akan mempengaruhi emosi pembaca (Oatley, 2002). Siswa dapat pula mempraktikkan penggunaan bahasa figuratif dalam cerita pendek mereka agar dapat menarik emosi pembaca melalui ceritanya.

\section{Pengimplementasian Menyimak Puisi dan Menulis Cerpen dalam Pembelajaran}

Pengimplementasian menyimak puisi dan menulis cerpen dalam pembelajaran bahasa Indonesia menggunakan pembelajaran kolaboratif. Dalam hal ini siswa berdiskusi dalam kelompok setelah menyimak puisi sehingga mereka dapat memahami puisi secara bersamasama. Hasil diskusi mereka mengenai pemahaman puisi serta pengetahuan baru yang mereka dapatkan dapat menjadi bekal dalam menulis cerita pendek secara mandiri. Skema rancangan pembelajaran integratif menyimak-menulis tersebut dapat dilihat pada gambar di bawah ini. 
GLRU

SISWA

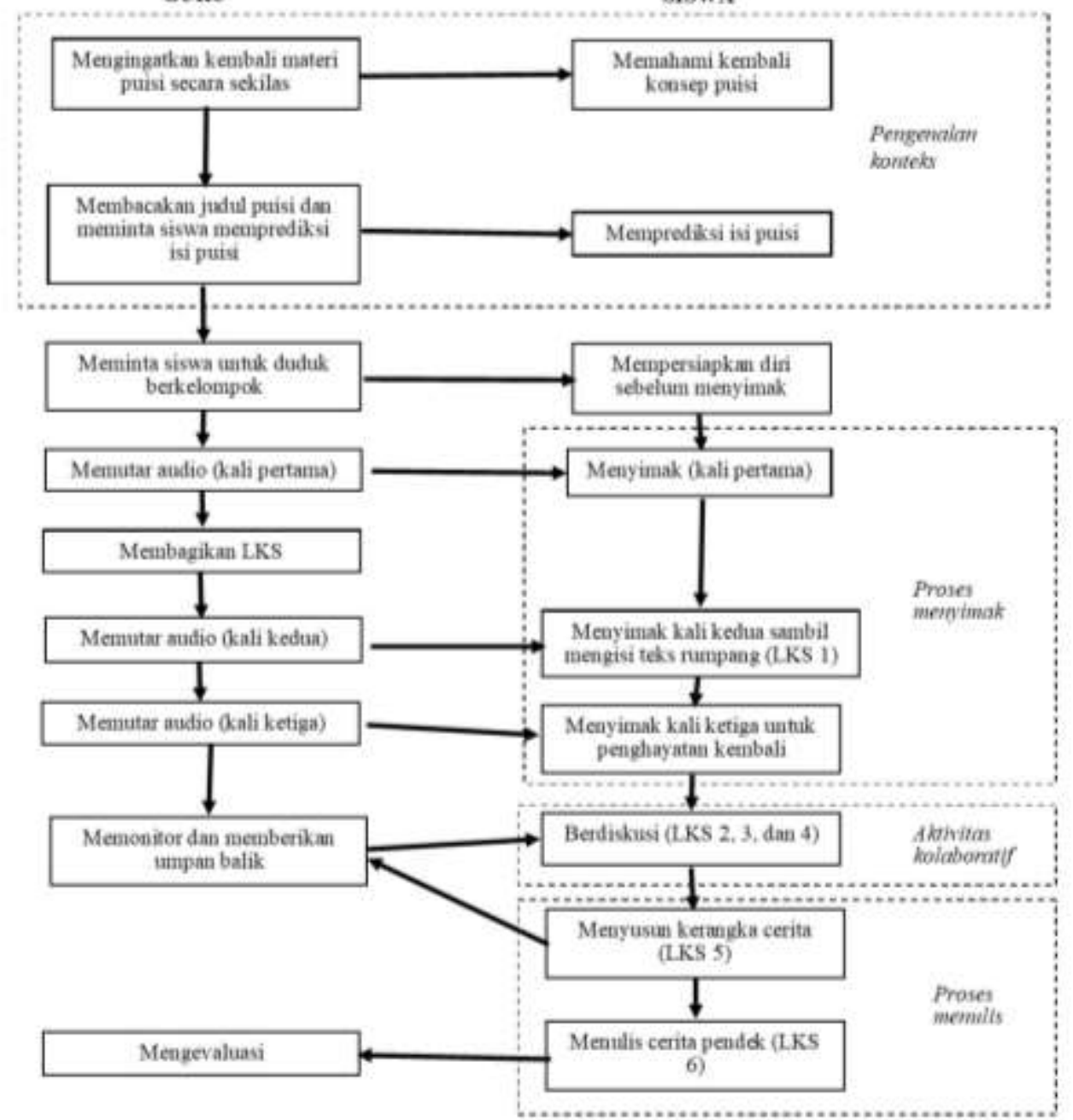

Gambar 2. Skema Rancangan Pembelajaran Integrasi Menyimak Puisi-Menulis Cerita Pendek

Penjabaran implementasi rancangan pembelajaran menyimak puisi dan menulis cerita pendek di atas dapatdapat dilihat pada tahap pembelajaran di bawah ini yang terdiri atas prapembelajaran, pembelajaran, dan pascapembelajaran.

a. Prapembelajaran

1. Guru menyampaikan kegiatan yang akan dilakukan dalam jam pelajaran kepada siswa, yaitu menyimak puisi dan menulis cerita.

2. Guru menyampaikan tujuan menyimak puisi dalam menulis cerita, yaitu untuk menstimulus imajinasi dan perkembangan bahasa siswa sebelum menulis cerita sehingga siswa terbantu dalam menemukan ide cerita.

b. Pembelajaran

1. Guru menyebutkan judul puisi yang akan diperdengarkan, yaitu Sajak untuk Hari Tиати karya Nermi Silaban dan meminta beberapa siswa memprediksi isi puisi berdasarkan judul tersebut.

2. Guru membagi siswa dalam beberapa kelompok dan meminta siswa bersiap-siap menyimak puisi 
3. Guru mengingatkan siswa agar menyimak dengan seksama sehingga siswa dapat memahami makna, menghayati suasana, dan menemukan majas-majas.

4. Guru mulai memperdengarkan rekaman puisi berupa audio atau video tanpa teks atau guru dapat membacakan puisi tersebut di depan kelas dengan intonasi, ekspresi, dan penghayatan yang tepat.

5. Guru membagikan LKS

6. Guru kembali memperdengarkan puisi untuk keduanya kalinya dan menyampaikan kepada siswa untuk bersiap-siap mengisi teks rumpang pada LKS 1

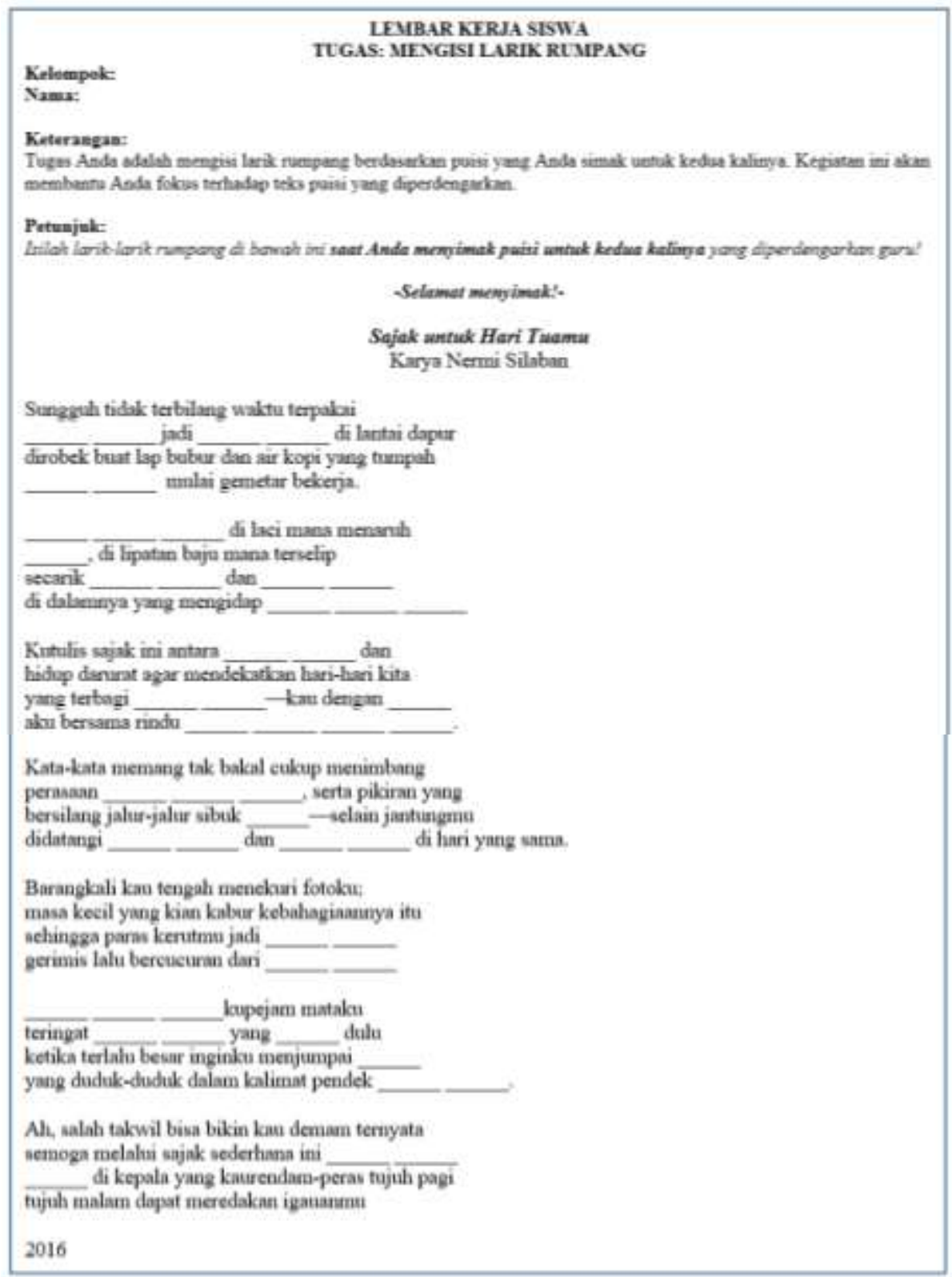

Gambar 3. LKS 1: Mengisi Larik Rumpang

(sumber puisi: Silaban, N. 2017. Bekal Kunjungan. Yogyakarta: Gambang Buku Budaya.) 
7. Setelah menyimak puisi dengan seksama dan mengisi teks rumpang, guru memperdengarkan kembali puisi tersebut agar siswa dapat mengecek ketepatan teks rumpang yang mereka isi pada LKS 1

8. Setelah pengecekan teks puisi pada LKS 1, guru meminta siswa mengisi LKS 2 s.d LKS 4 dan dapat berdiskusi dalam memahami isi puisi.

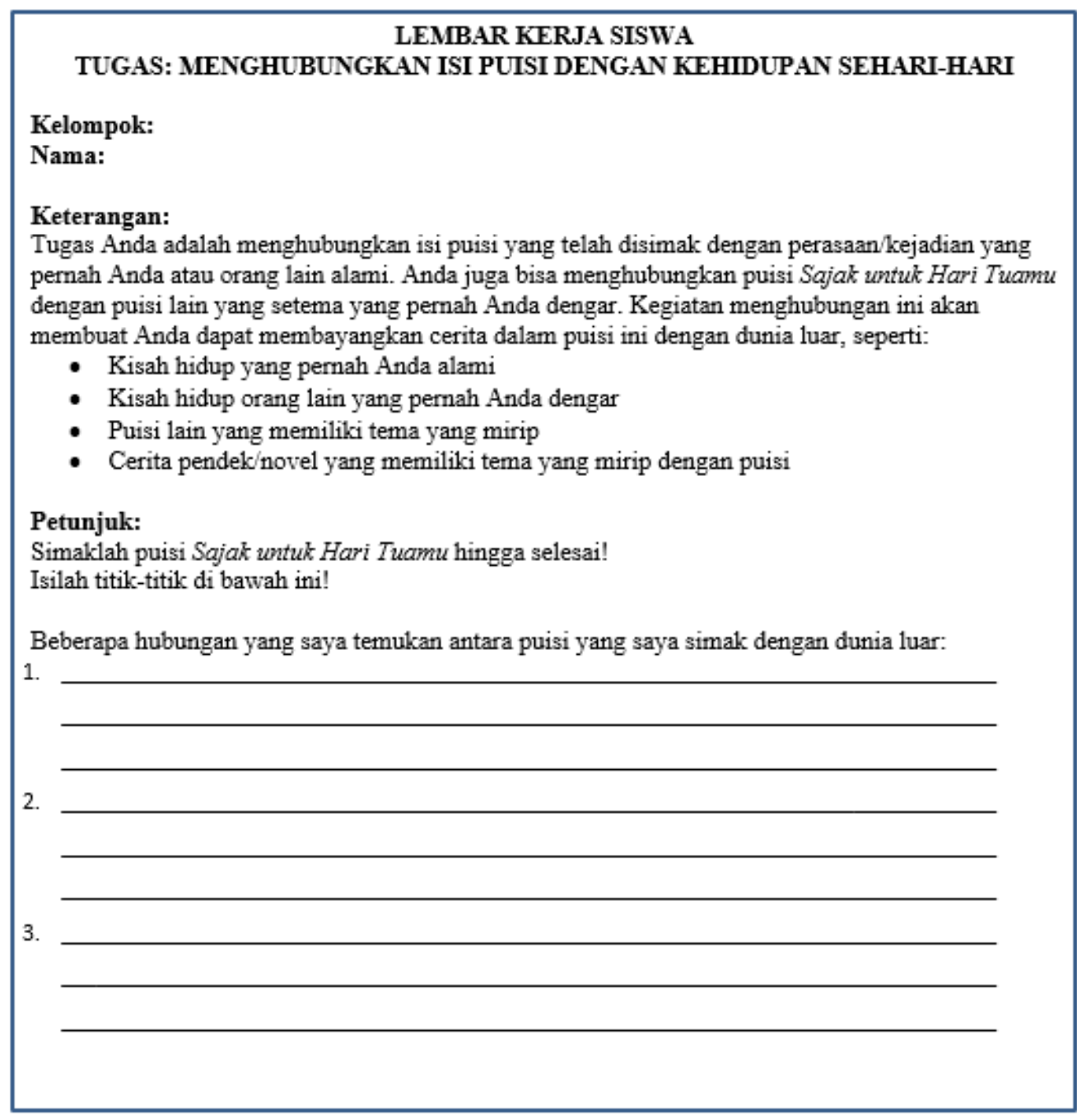

Gambar 4. LKS 2: Menghubungkan Isi Puisi dengan Kehidupan Sehari-hari 
LEMBAR KERJA SISWA

TUGAS: MENYIMPULKAN ISI PUISI

Kelompok:

Nama:

Keterangan:

Tugas Anda adalah menyimpulkan isi puisi yang telah disimak untuk mengetahui tema puisi tersebut.

Petunjuk:

Simaklah puisi Sajak untuk Hari Tuamu hingga selesai!

Setelah menyimak puisi, isilah isian di bawah ini!

Puisi Sajak untuk Hari Tuamu bercerita tentang seseorang yang:

Dengan demikian, puisi Sajak untuk Hari Tuamu memiliki tema, yaitu

Gambar 5. LKS 3: Menyimpulkan Isi Puisi 


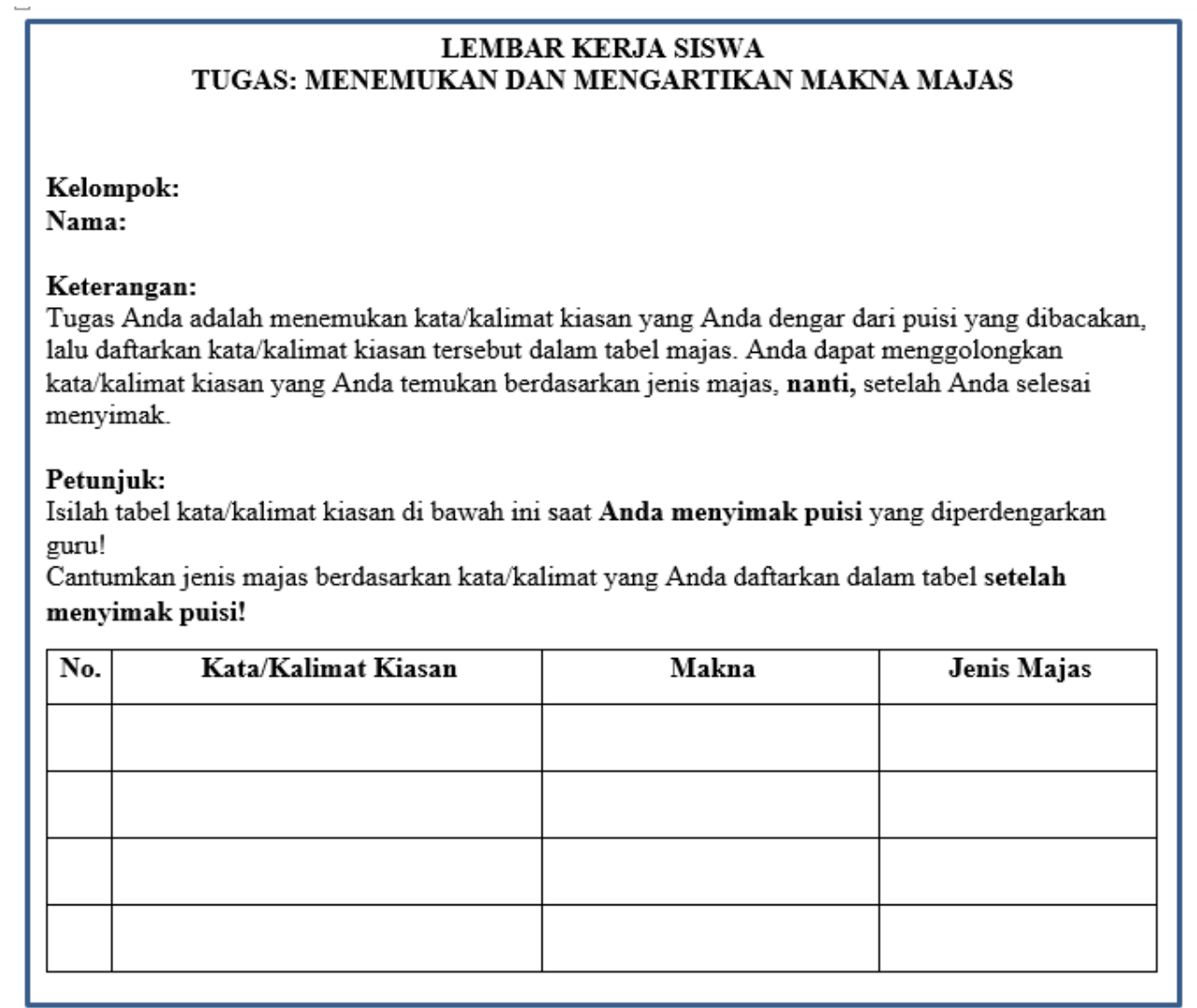

Gambar 6. LKS 4: Menemukan dan Mengartikan Makna Majas

9. Guru memonitori kegiatan diskusi siswa pada setiap kelompok.

10. Guru membahas beberapa hasil pengisian LKS siswa dan mengecek kesiapan siswa untuk menulis cerita berdasarkan puisi yang sudah disimak

11. Guru meminta siswa bersiap-siap mengerjakan LKS 5 (menulis kerangka cerita berdasarkan puisi yang disimak) secara mandiri 


\section{LEMBAR KERJA SISWA}

PRAMENULIS CERTA

Nama:

\section{Keterangan:}

Thagas Anda adalah menulis hasal diskusi berupa kemungkinan ide ode cerita yang muncul setelah menyimak poisi Sajak unhuk Hari Twamu dan setelah menahami secara bersama-sama isi puisi

yang telah disimak. Perlu disadari bahwa

1) Siswa yang mengisi lembar keja ntengisi seks rumpang dapat membantu teman-temannya untuk memahami bait yang disimak dan menggunakan bait tersebut sebagai unsur cerita (bagien kalimat, paragraf, ataupun judal) sena menentukan alur cerita

2) Siswa yang mengisi lembar keja mengíubungkan puiri dengan kehichupan sehari-hari dagut membantu saswa menentukan ide cerita betdasarikan puisi yans telah diranu menjadi konsep yang sedecthana.

3) Siswa yang mengisi lembar kerja mengartikan mabria mojas dapat membantu siswa memperikaya dikst dalam menuls cerita, menentukan latar waktu, tempat, dan suasana centa.

4) Siswa yang mengisi lembar kerja menyinpulkan ifi puisi dapat membantu siswa menulis cerita yang megand ung pesan yang sama denzan pesan yang terdapat dalam puisi.

Petunjuk:

Tulsalab ide ceritamu!

Saya akan menulis cerita tentang

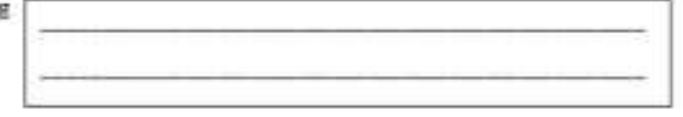

dengas tokoh sebagai berikut:

\begin{tabular}{l|} 
Nama: \\
Sifut:
\end{tabular}

Nama:

Sifat

dan kejadias dalam cerrta saya berlangune di

poda waktw:

(Beberapa) suasana yana tergambar dalam cerita, yaitu:

Layjutan Lembar Kerja Pramenulis Cerita

Alur cerita saya sebagai berikut*

Pengenalan Awal Cerita

1.

2

3.

Kemunculan Konfliks
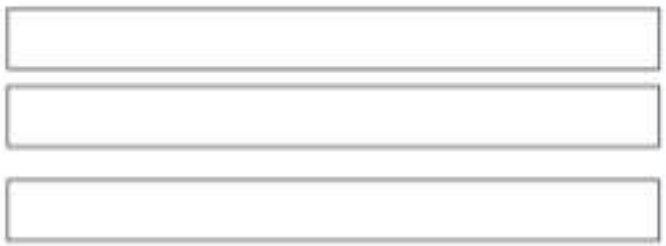


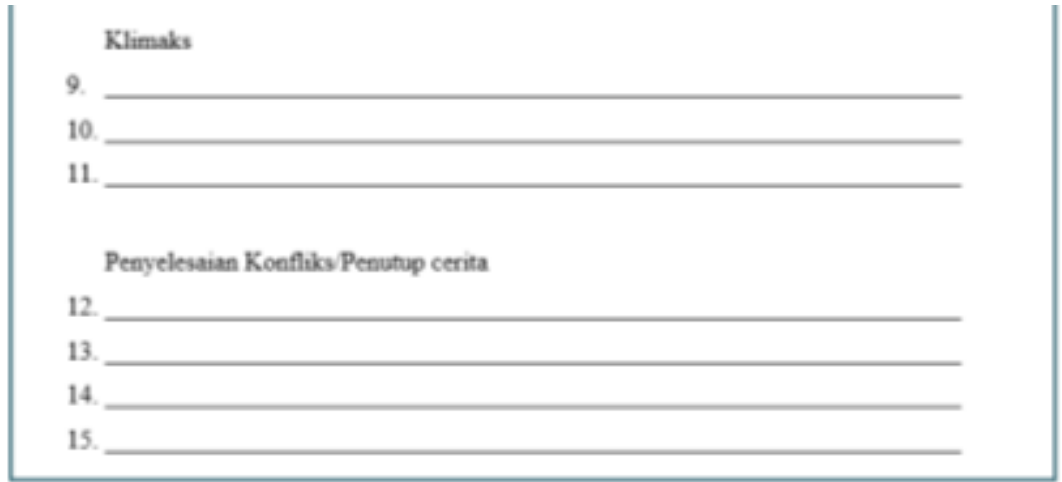

Gambar 7. LKS 5: Pramenulis Cerita

12. Guru meminta siswa mengerjakan LKS 6 (mengembangkan kerangka dan menulis cerita)

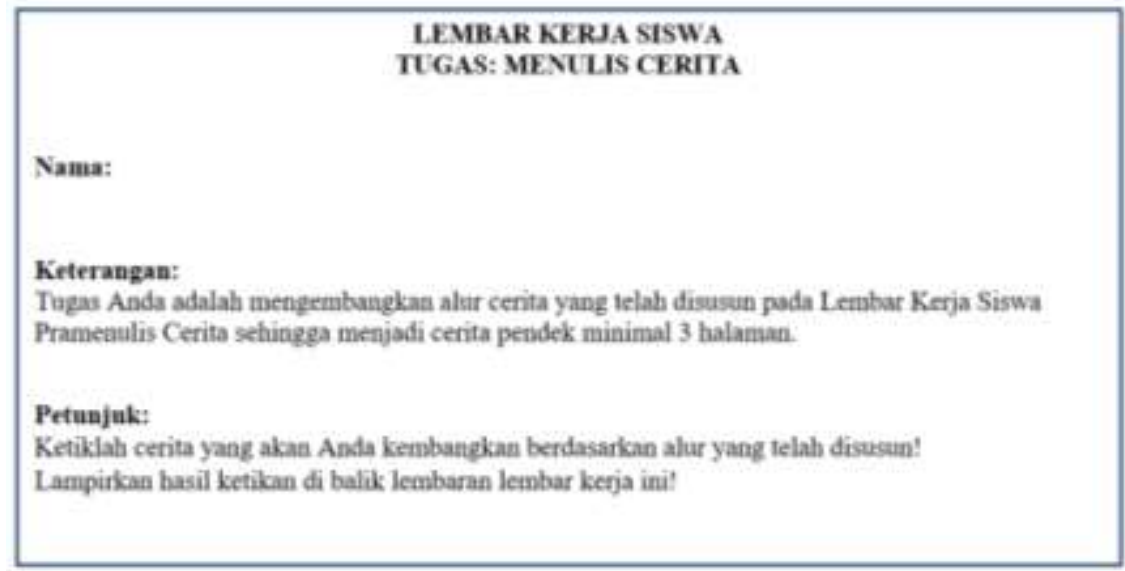

\section{Gambar 8. LKS 6: Menulis Cerita}

c. Pascapembelajaran

1. Guru memberikan umpan balik berupa catatan tertulis pada cerita pendek karya siswa.

2. Guru membuka ruang diskusi dengan siswa untuk mengaitkan hasil menyimak puisi serta pengaruhnya terhadap munculnya ide untuk menulis cerita pendek.

Guru memberikan penguatan mengenai pengaruh puisi yang telah disimak siswa terhadap cerita pendek yang siswa hasilkan.

\section{Simpulan}

Aktivitas menyimak puisi sebagai bahan pembelajaran menulis cerita pendek sejatinya harus dilakukan berulang kali. Dalam arti kata, menyimak puisi dalam pembelajaran bahasa Indonesia perlu dijadikan kebiasaan. Guru dapat membimbing siswa untuk menemukan situs atau tautan yang berisi puisi yang bisa disimak oleh siswa kapan saja dan di mana saja. Siswa dapat menyimak puisi secara mandiri untuk kemudian melaporkan hasil simakannya sebelum pembelajaran bahasa Indonesia dimulai. Aktivitas ini juga dapat tergabung dalam salah satu kegiatan dalam gerakan literasi di sekolah. Pembiasaan ini dilakukan agar siswa benar-benar mendapatkan manfaat dari menyimak puisi seperti yang telah dijelaskan dalam pembahasan di atas. 
Puisi memang dapat menjadi stimulus bagi siswa dalam menulis cerita pendek. Namun, kemampuan siswa dalam menulis cerpen tidak lepas dari kebiasaan siswa membaca dan menulis cerita pendek di luar kegiatan pembelajaran. Untuk teknis menulis cerpen siswa tetap perlu mempelajarinya lewat membaca cerita pendek. Idealnya, siswa perlu familiar dengan teks cerpen agar bisa menulis cerpen. Oleh karena itu, sama seperti menyimak puisi, menulis cerpen juga perlu menjadi pembiasaan melalui latihan. Guru dapat meminta siswa membaca satu cerpen di rumah dan diceritakan setiap jam pelajaran bahasa Indonesia. Aktivitas tersebut dapat dilakukan sejak awal tahun ajaran baru sehingga saat pembelajaran cerpen sudah dimulai siswa sudah familiar dengan teks itu.

Pembahasan mengenai keterkaitan menyimak puisi dengan menulis cerpen pada artikel ini diharapkan dapat dijadikan masukan untuk dimplementasikan dalam pembelajaran bahasa Indonesia. Selain itu, contoh Lembar Kerja Siswa (LKS) diharapkan dapat menjadi rujukan bagi pengajar dan peneliti dalam mengamati keterampilan menyimak siswa serta dampaknya terhadap keterampilan menulis cerita pendeknya.

\section{References}

Cazden, C. (1988). Classroom Discourse: The language of Teaching and Learning. Portsmouth, NH: Heinemann.

Chall, J. (2000). The Academic Achievement Challenge: What Really Works in the Classroom? New York, NY: Guilford Press.

Collins B. C. (2001). Teaching the Language Arts: Expanding Thinking through StudentCentred Instruction (2nd ed.). Boston, MA: Allyn \& Bacon.

Dewi, N. P. E. F., Martha I. N., dan Wendra, I. W. (2016). Kesulitan Belajar Keterampilan Menulis Cerita Pendek Siswa Kelas Ixc SMP Negeri 3 Singaraja Tahun Pelajaran 2016/2017. Jurnal Pendidikan Bahasa dan Sastra Indonesia Undiksha, 5(3): 1-12.

Dunn, M. \& Finley, S. (2010). Children's Struggles with the Writing Process: Exploring Storytelling, Visual Arts, and Keyboarding to Promote Narrative Story Writing. Multicultucal Education.

Harmer, J. (2007). The Practice Of English Language Teaching The Practice Of English Language Teaching (4th Ed.). USA: Pearson Education Limited.

Hughes, J. (2007). Poetry: A Powerful Medium for Literacy and Technology Development. Diakses di http://www.edu.gov.on.ca/eng/literacynumeracy/inspire/research/hughes.pdf

Oatley, K. (2002). Emotions and the Story Worlds of Fiction. In M.C. Green, J.J. Strange, \& T.C. Brock (Eds.) Narrative impact: Social and Cognitive Foundations, pp. 39-69.

Pratiwi, N. Y. (2019). The Analysis of Problems Encountered by Beginner Writer In Writing A Short Story: A Case Study in Creative Writing Class. Indonesian Journal of Educational Research and Review, 2(3): 402-407.

Putra, D. P. (2013). Kemampuan Menulis Cerpen Siswa Kelas X 1 SMA Negeri 1 Melaya Ditinjau dari Unsur Intrinsik. Jurnal Pendidikan Bahasa dan Sastra Indonesia Undhiksa, 1(8):1-12.

Semi, M. A. (2008). Stilistika Sastra. Padang: UNP Press.

Syafrina, D. (2017). Pengembangan Model Lintaskujitu dalam Pembelajaran Menyimak Fabel untuk Siswa Kelas VII SMP. Tesis. Malang: Universitas Negeri Malang.

Syafrina, D., Dermawan, T., dan Widiati, N. (2017). Implementasi Pembelajaran Menyimak di Sekolah Menengah Pertama. Jurnal Pendidikan: Teori, Penelitian, dan Pengembangan, 2(5): 706-713. 
Umar, S. (2016). Peningkatan Keterampilan Menulis Cerpen dengan Strategi Copy The Master Melalui Media Audiovisual pada Siswa Kelas IX A SMP Negeri 2 Tolitoli. Jurnal Kreatif Tadulako Online, 4(6): 282-300

Wassiliwizky, E., Koelsch, S., Wagner, V., Jacobsen, T., \& Menninghaus, W. (2017). The Emotional Power of Poetry: Neural Circuitry, Psychophysiology and compositional Principles. Social Cognitive and Affective Neuroscience, 12(8):1229-1240.

Watts-Taffe, S., \& Truscott, D. (2000). Using What We Know about Language and Literacy Development for ESL Students in the Mainstream Classroom. Language Arts, 77(3): 258-264. 